\title{
R8 - DESENVOLVIMENTO DO TESTE DE IMUNOFENOTIPAGEM PARA A CONTAGEM DE LINFÓCITOS TCD4+
}

$\underline{\text { Marli Sidoni }}^{1}$, Marta de Almeida Santiago ${ }^{1}$, Roberto Calado da Silva ${ }^{1}$, Hilton Jorge do Nascimento $^{2}$, José Godinho da Silva Junior ${ }^{2}$, Edimilson Domingos da Silva ${ }^{1}$, Antonio G. P. Ferreira ${ }^{3}$.

${ }^{1}$ Laboratório de Tecnologia Diagnóstica, Bio-Manguinhos, Fiocruz

${ }^{2}$ Laboratório de Macromoléculas, Bio-Manguinhos, Fiocruz

${ }^{3}$ PRED- Gerencia de Programa de Reativos para Diagnóstico, Bio-Manguinhos, Fiocruz

Objetivo: Desenvolver insumos alternativos para a contagem das subpopulações linfocitárias T CD3/CD4/CD8/CD45. A proposta de nacionalização dos processos de obtenção dos Anticorpos Monoclonais, bem como todos os processos de conjugação e avaliação dos insumos que compõem o produto complementam as ações, visando à futura implementação na Rede Pública de Saúde do País.

Método: A cooperação técnica estabelecida entre Bio-Manguinhos/Fiocruz e o Centro de Imunologia Molecular (CIM) de Cuba possibilitou a aquisição dos anticorpos monoclonais anti-CD3/CD4/CD8/CD45 que foram marcados com quatro fluorocromos: isotiocianato de fluoresceína, ficoeritrina, cianina 5 e ao tandem ficoeritrina-cianina 7 , para identificação dos marcadores celulares por citometria de fluxo.

Entretanto, a interpretação clínica é dada pelos percentuais e valores absolutos das populações linfocitárias. Para tanto, foram utilizadas microesferas comerciais para a avaliação imunológica do estado do paciente.

Resultado: Foram avaliadas amostras de cerca de 100 indivíduos infectados pelo HIV e submetidos a tratamento com antirretrovirais. Os resultados obtidos não apresentaram diferenças estatísticas significativas entre os valores dos anticorpos monoclonais conjugados em Bio-Manguinhos frente ao teste comercial utilizado, atualmente, na Rede Nacional de Laboratórios para Contagem de linfócitos T CD4+ formada por 90 laboratórios distribuídos pelo País. 
Conclusão: $\mathrm{O}$ produto/kit em desenvolvimento em Bio-Manguinhos poderá ser utilizado visando o monitoramento da evolução clínica de indivíduos infectados pelo HIV ou quando da introdução de terapias com antirretrovirais em novos pacientes. Esse monitoramento possibilita a adoção de terapias preventivas às infecções oportunistas e busca a efetividade do tratamento. 